\title{
Childhood cognitive ability and adult academic attainment: evidence from three British cohort studies
}

\author{
Ingrid Schoon \\ Institute of Education, London \\ I.Schoon@ioe.ac.uk
}

(Received May 2010 Revised June 2010)

\section{Abstract}

This paper examines the association between general cognitive ability directly measured at age 10/11, and adult academic attainment in three British birth cohorts born in 1946, 1958, and 1970, controlling for family socio-economic background and gender. The study uses structural equation modeling to link latent variables indicating family socio-economic background, childhood general cognitive ability, and academic attainment, assessed through school leaving age and highest qualifications achieved by age 26. In addition, logistic regression modeling is used to establish the odds of obtaining degree level qualifications in times of social change. The results show that the association between family social background and academic attainment has remained more or less the same over time, gender inequalities have reduced, while the association between general cognitive ability and academic attainment has decreased for the 1970 cohort. Although more young people achieve degree level qualifications in the later born cohort, the findings suggest persisting social inequality in the realisation of cognitive potential and educational opportunities. The findings are discussed in terms of their policy implications.

\section{Introduction}

The aims of this paper are threefold. First, to examine changes in the association between family socio-economic background, general cognitive ability and academic attainment in a changing sociohistorical context. Second, to assess gender differences in the associations. Third, to assess the predictive power of social background, gender, general cognitive ability and the interactions between these variables for gaining a degree level qualification in a changing social context. The study will draw on evidence from three British birth cohorts born in 1946, 1958 and 1970 respectively. The three birth cohorts were born at crucial turning points in British social history, as the 1946 cohort grew up during a period of extraordinary economic growth and social transformation which started after the post-war years and ended in the mid 1970s (see Sutherland, this issue). Eric Hobsbawm (1995) had described this period as a 'Golden Age' which was followed by the 'Crisis Decades'. The 1958 cohort completed their compulsory education in 1974 and made the transition into the labour market at the beginning of a major economic recession, while the 1970 cohort reached compulsory school leaving age in 1984, just at the height of the 1980's recession. Evidence from the three birth cohorts will thus provide crucial information about changes in educational opportunities in times of social change, and can assess changes in the odds of realizing one's cognitive potential. 


\section{Socio-historical change}

There is persisting evidence of the positive association between general cognitive ability, academic attainment and career success (Deary, Strand, Smith, and Fernances 2007; Gottfredson 1997; Jensen 1998; Mackintosh 1998; Sternberg, Grigorenko and Bundy 2001). Yet a number of key questions regarding this association have remained unanswered, especially those regarding historical changes in the relationship between cognitive ability and career success, and the role of family socioeconomic status in shaping both childhood cognitive ability and later attainments (Strenze 2007). The role of these interlinked variables in predicting academic attainment in times of social change is generally difficult to disentangle, especially due to the lack of suitable longitudinal studies, enabling the comparison of similar indicators in different age cohorts. Furthermore, the role of historical changes in the relationship between general cognitive ability and socio-economic success is a particularly controversial issue, following the publication of the 'Bell Curve' by Hernstein and Murray (1994). These authors argue that the association between mental ability and career success has been growing in western societies throughout the $20^{\text {th }}$ century, and that cognitive ability is becoming more important in influencing where one ends up in the socio-economic hierarchy. Although some studies have found support for this thesis of achievement over ascription (Murnane, Willet and Levy 1995; Saunders 1997, 2002), there is also contradictory evidence, calling into question the increasing importance of general cognitive ability in shaping career success (Bowles 1972; Flynn 2004; Hauser and Huang 1997). Reviewing evidence from eleven surveys conducted in the USA between 1928 and 1974, Jencks and colleagues (1979) found no clear trend in the correlations between cognitive ability and socio-economic success. Evidence from the UK, drawing on data collected for the 1946 and the 1958 cohort, showed a reduced association between childhood cognitive ability and adult educational attainment for the later born 1958 cohort (Richards, Power and Sacker 2009). Furthermore, findings from a comparison of data collected for the 1958 and 1970 cohort, suggests that the association between general cognitive ability and adult socio-economic status is further declining (Breen and Goldthorpe 2001; Schoon 2008).

In the UK, the 1944 Education Act was introduced with the aim of increasing educational opportunities irrespective of financial means or socio-economic background, and to raise the overall educational level in the population (Kerckhoff and Trott 1993; Sutherland, this issue). During the 'Golden Age' (Hobsbawm, 1995), educational spending had been growing, while after the mid-1970s it started to fall, followed by a recovery in the 1990s. At the same time, education and employment opportunities have changed dramatically. Between 1951 and 1991 the United Kingdom witnessed a significant decline in manual jobs, while employment in clerical occupations has increased, and work in professional and managerial professions has tripled (Gallie 2000). Following the introduction of new technologies and the disappearance of manual jobs, increasing numbers of young people are expected to participate in further education beyond compulsory schooling age (Bynner and Parsons 2002; Furlong and Cartmel 1997; Rosenbaum 2001), and during the last two decades a growing number of young people have participated in higher education, once the preserve of a privileged minority (Blossfeld and Shavit 1993; Bynner 2005; McVicar and Rice 2001). Some have taken increased education participation as indicating that talented individuals from less privileged backgrounds are taking advantage of expanding opportunities to gain educational credentials (Bond and Saunders 1999; Saunders 1997). On the other hand, it has been argued that the not so able individuals from privileged backgrounds have benefited most from the educational expansion, i.e. that although absolute rates of education participation have increased, relative differences between individuals from different social backgrounds have remained (Blanden and Machin 2003; Bynner and Joshi 2002; Galindo-Rueda and Vignoles 2005; Marshall, Swift and Roberts 1997; Schoon 2008). 


\section{Gender differences}

Another aspect to be addressed in this paper is the gender gap in academic attainment. Until recently, the majority of research on gender differences in educational opportunities and attainment had focused on the ways in which girls are disadvantaged in comparison to boys. Until the early 1970s, young women tended to gain fewer formal qualifications and were generally underrepresented in the Universities. By the early 1980s the situation started to change, and girls began to catch up with or even overtake boys in their academic attainments (Arnot, David, and Weiner 1999; Francis 2000). The 'underachievement' of boys has to some extent brought about something of a moral panic, with appeals to the government to act in support of struggling boys (Epstein, Elwood, Hey and Maw 1998; Younger and Warrington 2006). The success and achievements of girls in the school system, on the other hand, has been hailed as a story of extraordinary success of post-war egalitarian movements. It has been argued that prior to the 1970s, boys and girls were educated for very different occupational and domestic roles (Riddell 2000), while the 1975 Sex Discrimination Act made it unlawful to treat girls differently from boys regarding access to courses, and educational and occupational opportunities. On the other hand, continuing inequalities and persistent disadvantages for women regarding subject choice and opportunities in higher education and socio-economic status attainment have received less attention (Francis 2002; Marini and Fan 1997; Tinklin 2003). Although women make up more than half of higher education students and almost half of the labour force, proportionately fewer women than men rise to the top of their professions (Crompton 2006; Farmer 1997, 2006). There continue to be barriers and obstacles to female career development, as reflected in gender role stereotypes, gender discrimination, and occupational sexsegregation (Scott, Dex, Joshi, Purcell and Elias 2008).

\section{The Model}

Changes in the associations between social background, academic ability, educational attainment, and gender will be examined in three British birth cohorts. It is assumed that, following the introduction of the 1975 Sex Discrimination Act and the increasing expansion of further and higher education, the association between gender, social background and academic attainment is decreasing for the later born cohorts. To test this assumption, the study will advance methodologically from previous studies by using structural equation modeling (SEM) as well as multiple regression analysis. Using latent variables instead of directly observed measures, facilitates a comparative approach to data collected during different sociohistorical periods and with different assessments (Bollen 1989).

\section{Figure 1. The Model}

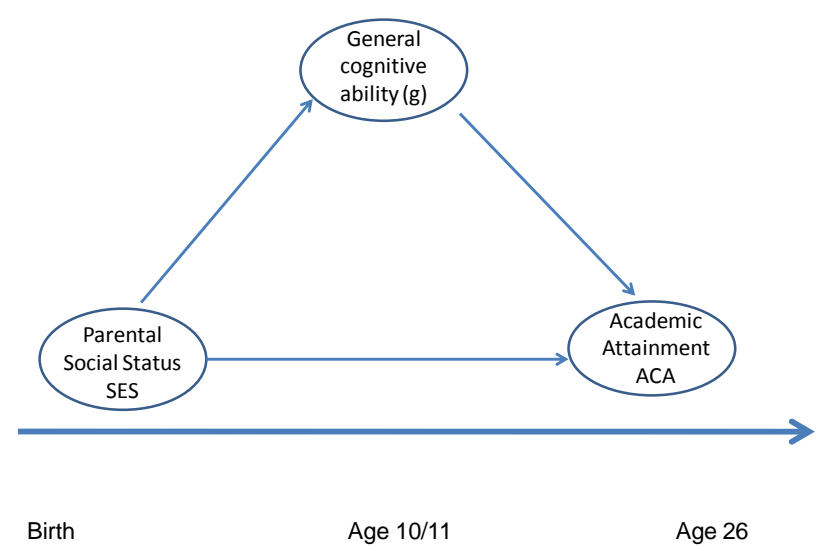


Figure 1 illustrates the associations to be tested in all three cohorts. The usual SEM conventions are used, with latent variables shown as oval shapes. Singleheaded arrows represent causal influences. Unique and error variance for each manifest variable and disturbance on the latent variables are included in the model (not shown in the diagram). Family social status at birth is assumed to be associated with general cognitive ability in mid-childhood, and both variables are assumed to shape later academic attainment. Family social position is indicated through the combination of father's occupational status and mother's education, following the assumption that a single social class measure might be an unreliable and incomplete indicator of social status (Korenman and Winship 2000; Lampard 1995), and that the combination of occupational class and education can be used to indicate social position, reflecting socio-economic resources as well as cultural characteristics relevant to the study of life chances (Gershuny 2000). Academic attainment in young adulthood is indicated by the age at leaving full-time education and highest qualifications achieved by age 26 .

\section{Method}

\section{Samples}

The study draws on three national birth cohort studies: the 1946 National Survey of Health and Development (NSHD), 1958 National Child Development Study (NCDS), and the 1970 British Cohort Study (BCS70) following the lives of cohort members from birth into adulthood. Each of the studies covers England, Wales and Scotland and their populations represent the national population of the same age (Ferri, Bynner and Wadsworth 2003). The 1946 cohort (Wadsworth et al 2005) followed a third of all individuals born within one week in the year in question $(n=5,362)$, and the later two studies followed up all individuals born within a chosen week, comprising 17,414 cohort members born in 1958 and 17,198 born in 1970 . The analytic samples are based on cohort members with complete information on parental socio-economic status and direct cognitive assessments at age 10 or 11 , which was then linked to information on academic attainments by age 26 , comprising 3,730 cohort members of the 1946 cohort, 9270 of the 1958 cohort and 7,310 of the 1970 cohort. Compared to the analytic samples, those individuals who did not complete the adult follow-up sweeps had a lower score on the test of general cognitive ability and a more disadvantaged family social background. To account for sample attrition and missingness between survey sweeps we used multiple imputation, as described in the section on statistical analysis.

\section{Measures \\ Family social status at birth}

Family social status is indicated by parental occupational social class and maternal education. Parental occupational social class was measured through the father's current or last held job, coded according to the Registrar General's measure of social class (RGSC). The RGSC is defined according to job status and the associated education, prestige (OPCS and Surveys, 1980) or lifestyle (Marsh, 1986). It is coded on a six-point scale: I professional; II managerial and technical; IIINM skilled non-manual; IIIM skilled manual; IV partly skilled; V unskilled (Leete and Fox 1977)'. Class I represents the highest level of prestige or skill and class $V$ the lowest. Maternal education is coded as a dichotomous variable indicating whether or not the mother has participated in further education beyond compulsory school leaving age.

\section{Childhood cognitive ability at age 10/11 years}

Childhood cognitive ability was assessed differently in the three cohorts. In the 1946 cohort, general cognitive ability was assessed at age 11 years, using a verbal and non-verbal test, both devised by the National Foundation for Educational Research (NFER) (see also Richards, Stephen and Mishra, this issue). In the 1958 cohort a general ability test has been completed by cohort members at age 11, comprising the assessment of both verbal and non-verbal skills. Scores from this test correlate strongly with scores on an IQ-type test used for secondary school selection $(r=0.93)$, suggesting that the test can serve as a good proxy for IQ scores (Douglas, 1964). In the 1970 cohort a modified version of the British Ability Scales (BAS) was directly administered at age 10 (Elliott, Murray and Pearson 1979), using four sub-scales: word definitions and word similarities were used to measure verbal ability, and recall of digits and 
matrices was used to measure non-verbal ability. For all three cohorts, a principal components analysis (PCA) was carried out for each of the verbal and nonverbal sub-tests, in order to establish the presence of a general cognitive ability factor (g). In all three cohorts, the examination of the scree slope suggested the presence of a single component. The first principal component scores were saved for each subject as an indicator of each person's general cognitive ability (g) and were standardised to a mean of 0 and an SD of 1.

\section{Academic attainment by age 26}

Academic attainment was indicated by age at leaving full-time education, and the highest educational qualifications achieved by age 26 . In all three cohorts, a broad classification of academic and vocational qualifications based on a scale related to the National Vocational Qualification (NVQ) levels was used (Makepeace, Dolton, Woods, Joshi and Galinda-Rueda 2003), differentiating between cohort members who had left school with no qualifications, those with qualifications up to NVQ level 2 (equivalent to GCSE or ordinary secondary qualifications and their training equivalents), those with advanced secondary education or NVQ level 3 ('A' levels or university entry qualifications and their equivalents), or NVQ level 4 and above (degree level or equivalent).

\section{Statistical analysis}

All SEM analyses were carried out using the software package Mplus v5 (Muthén and Muthén 2007). The program applies a robust full information EM estimator that corrects for bias under the assumption that missing data are missing at random, which means that 'missingness' is permissible even when it is related to covariates or outcomes, so long as covariate status does not determine presence or absence of data (Little and Rubin 2002). Probit regressions were used, based on robust weighted least squares estimation. Because of the ordered categorical variables which functioned as both independent and dependent, the theta parameterization was necessary. Estimation is based on the covariance matrices between observed variables for all patterns of missing data in the other observed variables. Regression estimates convert probit estimates for ordinal dependent variables to a common metric that allows comparison with standardised linear regression estimates for the continuous variables.

In line with current practice, several criteria were used to assess the fit of the data to the model. The $\chi^{2}$ statistic is overly sensitive to model misspecification when sample sizes are large, or the observed variables are non-normally distributed. The root mean square error of approximation (RMSEA) gives a measure of the discrepancy in fit per degrees of freedom (<.05 indicates a good fit). The final index of choice is the comparative fit index (CFI) where values above .95 indicate acceptable fit (Bentler 1990).

In addition to SEM, multiple logistic regression analysis was used to assess the predictive power of social background, general cognitive ability and gender, in predicting who gains a degree level qualification in times of social change, pooling information from the different data sets.

\section{Results}

Table 1 gives the descriptive statistics of the categorical variables used in the model. There has been an upward shift in the distribution of parental social class. In the 1946 cohort, 85 per cent of fathers were in a manual occupation, compared to about two-thirds of fathers of the 1958 and 1970 cohort. There also has been an increase in professional and managerial occupations among fathers of the later born cohorts. About two-thirds of mothers of the 1946 and 1970 cohort left school a minimum age, compared to three quarters of mothers of the 1958 cohort. It has to be kept in mind that after World War II the minimum school leaving age was raised to 15 years. In 1972 compulsory school leaving age was increased from 15 to 16, with the 1958 cohort members being the first cohort to remain in school until age 16. However, in both the 1958 and 1970 cohort there were a small number of young people who left school before compulsory school leaving age.

By age 26 only about one in ten individuals born in 1946 succeeded in gaining degree level qualifications, compared to about a fifth in the 1958 cohort and nearly a third in the 1970 cohort.

There were no gender differences regarding the socio-demographic background variables. However, 
while in the 1946 cohort, fewer women than men stayed on in full-time education beyond age 15 (27 per cent of men versus 22.8 per cent of women), women in the later-born cohorts are catching up, with 32.4 per cent of men and 39.1 per cent of women in the 1958 cohort and 40.4 per cent of men versus 49.8 per cent of women in the 1970 cohort, staying on beyond age 16. Likewise in the 1946 cohort, fewer women than men succeeded in gaining a degree level qualification (5.4 per cent of women compared to 13.1 per cent of men) while in the later born cohorts, gender parity was more or less achieved in this respect.

Table 1. Descriptive Statistics of Cohort Characteristics (in percent)

\begin{tabular}{|c|c|c|c|}
\hline & 1946 Cohort & 1958 Cohort & 1970 Cohort \\
\hline Gender (\% male) & 52.5 & 51.7 & 48.1 \\
\hline \multicolumn{4}{|l|}{ Father's occupational status } \\
\hline Professional & 2.3 & 4.7 & 5.0 \\
\hline Managerial & 6.1 & 14.7 & 12.5 \\
\hline Skilled non-manual & 6.6 & 10.6 & 15.3 \\
\hline Skilled manual & 45.1 & 50.1 & 46.0 \\
\hline Semi-skilled & 30.2 & 11.4 & 15.6 \\
\hline Unskilled & 9.7 & 7.9 & 5.6 \\
\hline \multicolumn{4}{|l|}{ Mother's education } \\
\hline Left education at min. age & 64.2 & 75.0 & 64.4 \\
\hline \multicolumn{4}{|l|}{ Age left education } \\
\hline 15 & 54.5 & 3.4 & 2.3 \\
\hline 16 & 20.5 & 58.0 & 52.1 \\
\hline $17-18$ & 23.0 & 19.6 & 24.9 \\
\hline $18+$ & 2.0 & 16.1 & 20.7 \\
\hline \multicolumn{4}{|l|}{ Highest Qualifications } \\
\hline None & 38.6 & 12.1 & 3.3 \\
\hline NVQ1-2 (some) & 27.2 & 48.9 & 47.3 \\
\hline
\end{tabular}


(Table 1 cont'd)

\begin{tabular}{|l|c|c|c|}
\hline NVQ3 (A-level) & 24.7 & 17.3 & 18.0 \\
\hline NVQ4 (degree) & 9.5 & 21.7 & 31.4 \\
\hline $\mathrm{N}$ & 3730 & 9270 & 7310 \\
\hline
\end{tabular}

Table 2 gives the bivariate correlations between the observed variables. General childhood cognitive ability (g), indicated by the PCA factor scores, shows moderate associations with the parental social status indicators, with little variation in size between the cohorts. The correlations between $\mathrm{g}$ and academic attainment, i.e. age leaving school and highest qualifications, were moderate to strong and weaken over time. Furthermore, there appears to be a reduction in the strength of correlation between academic attainment and parental socio-economic background, possibly reflecting increasing education participation of relative disadvantaged young people, which is also shown by Gregg and Macmillan (this issue).

There were significant gender differences in general cognitive ability as well as academic attainment. Women in the 1946 and 1958 cohorts score higher than men in the cognitive assessment, while in the 1970 cohort they score lower than men.
In all three cohorts, women were less likely than men to obtain higher level qualifications, although, with the exception of the 1946 cohort, they were more likely to stay on longer in full-time education. The question of gender differences in cognitive ability continues to be debated, and there is uncertainty about their extent, or their even existence (Jensen 1998; Lynn 1999; Mackintosh 1996). Evidence from the UK suggests that even when sex differences in mean IQ scores are found, they tend to be small, with greater variance among boys (Deary, Strand, Smith, and Fernances 2007; Dykiert, Gale and Deary 2009; Strand, Deary and Smith 2006). However, it must also be kept in mind that cognitive ability scores obtained in the different cohorts are not directly comparable, as they have been assessed with different test instruments. Furthermore, there had been sample restrictions from the baseline population, with fewer males than females participating in the follow-up sweeps, especially in the 1970 cohort. 
Table 2. Bivariate correlations in the 3 cohorts

\begin{tabular}{|c|l|l|l|}
\hline & 1946 Cohort & 1958 Cohort & 1970 Cohort \\
\hline Correlation with general ability (g)\# & & & \\
\hline Father's occupational status & $-.337^{*}$ & $-.297^{*}$ & $-.304^{*}$ \\
\hline Mother's education & $-.311^{*}$ & $-.255^{*}$ & $-.305^{*}$ \\
\hline Age leaving ft education & $.540^{*}$ & $.466^{*}$ & $.364^{*}$ \\
\hline Highest qualifications & $.556^{*}$ & $.482^{*}$ & $.412^{*}$ \\
\hline Gender & $.072^{*}$ & $.067^{*}$ & $-.040^{*}$ \\
\hline Correlation with age leaving ft education & & & \\
\hline Father's occupational status & $-.432^{*}$ & $-.367^{*}$ & $-.322^{*}$ \\
\hline Mother's education & $-.403^{*}$ & $-.326^{*}$ & $-.317^{*}$ \\
\hline Highest qualifications & $.714^{*}$ & $.638^{*}$ & $.593^{*}$ \\
\hline Gender & $-.039^{*}$ & $-.043^{*}$ & $.066^{*}$ \\
\hline Correlation with highest qualification & $-.403^{*}$ & $-.288^{*}$ & $-.086^{*}$ \\
\hline Father's occupational status & $-.116^{*}$ & $-.052^{*}$ & \\
\hline Mother's education & & & \\
\hline
\end{tabular}

\section{Notes}

\# General cognitive ability $(\mathrm{g})$ is here measured by the factor score of the Principal Component Analysis, which has a mean of 0 and a standard deviation of 1 .

$* p<0.001$

Table 3 gives the estimates for the SEM model depicted in Figure 1, which was run separately for each cohort. The numerical values refer to standardized regression weights, taking into account all variables in the model simultaneously. The model has two components: one giving the relationships between the latent variables and their indicators (the measurement model), and the other defining the relationships among the latent variables (the structural model). Information is also provided for the model fit. The measured variables loaded strongly on the latent variable, all path coefficients were significant at the $5 \%$ level or less (parameter estimates divided by their standard errors), and the model showed a good fit. In the 1946 cohort the model explained 75 per cent of variance in academic attainment, in the 1958 cohort 51 per cent, and in the 1970 cohort 54 per cent. 
Table 3. Results from the Structural Equation Model, linking Parental Social Status to general ability and academic attainment: Standardised Estimates, standard errors, and model fit

\begin{tabular}{|c|c|c|c|}
\hline Measurement Model & 1946 Cohort & 1958 Cohort & 1970 Cohort \\
\hline \multicolumn{4}{|l|}{ Parental Social Status (SES) } \\
\hline Father's occupational status & $.68(.01)$ & $.65(.01)$ & $.62(.01)$ \\
\hline Mother's education & $.77(.02)$ & $.73(.01)$ & $.72(.01)$ \\
\hline \multicolumn{4}{|l|}{ General Ability (g) } \\
\hline Verbal ability (BCS: definitions) & $.93(.01)$ & $.90(.01)$ & $.81(.01)$ \\
\hline Verbal ability (BCS: similarities) & & & $.75(.01)$ \\
\hline Nonverbal ability (BCS: matrixes) & $.87(.01)$ & $.88(.01)$ & $.56(.01)$ \\
\hline Nonverbal ability (BCS: digits) & & & $.40(.01)$ \\
\hline \multicolumn{4}{|l|}{ Academic Attainment (ACA) } \\
\hline Age leaving $\mathrm{ft}$ education & $.92(.01)$ & $.88(.01)$ & $.86(.01)$ \\
\hline Highest qualifications at age 26 & $.89(.01)$ & $.87(.01)$ & $.76(.01)$ \\
\hline \multicolumn{4}{|l|}{ Pathway Coefficients } \\
\hline $\mathrm{SES} \rightarrow \mathrm{g}$ & $-.54(.02)^{\mathrm{ab}}$ & $-.48(.01)^{\mathrm{ac}}$ & $-.60(.01)^{b c}$ \\
\hline $\mathrm{SES} \rightarrow \mathrm{ACA}$ & $-.57(.02)^{\mathrm{ab}}$ & $-.49(.02)^{\mathrm{ac}}$ & $-.54(.03)^{\mathrm{bc}}$ \\
\hline $\mathrm{g} \rightarrow \mathrm{ACA}$ & $.41(.02)^{b}$ & $.41(.01)^{c}$ & $.27(.02)^{b c}$ \\
\hline \multicolumn{4}{|l|}{ Model Fit } \\
\hline$X^{2}(d f)$ & $18.11(6)$ & $112.04(6)$ & $166.94(15)$ \\
\hline CFI & 0.999 & 0.996 & 0.989 \\
\hline RMSEA & 0.024 & 0.037 & 0.035 \\
\hline $\mathrm{N}$ & 3730 & 9270 & 7310 \\
\hline
\end{tabular}

Note. Differences in pathway coefficients between cohorts were tested using t-tests. Significant $(p<.001)$ differences are indicated through letters a-c:
a -1946 and 1958
b -1946 and 1970
c- 1958 and 1970 
The standardized regression weights linking parental social status with childhood cognitive ability were significant, and the association increases over time, especially between assessments for the 1958 and 1970 cohort. Although the association was strong, it does not explain more than a quarter (in the two older birth cohorts) to a third of the variation in cognitive ability (in the youngest cohort). Both family socio-economic background and childhood cognitive ability were significantly associated with academic attainment. The association between parental social background and academic attainment remained more or less of similar strength for the three cohorts, although, compared to the 1958 cohort, it appears to have increased for the 1970 cohort. On the other hand, the association between childhood general cognitive ability and academic attainment has reduced for the 1970 cohort.

The model was also fitted for men and women separately for the three cohorts. Multiple group analysis suggests significant gender differences in the estimated coefficients, although the actual coefficients for men and women in the different cohorts are quite similar. Table 4 shows the standardized estimates, standard errors and model fit for men and women in the three cohorts separately.

For men in the 1946 and 1958 cohort, the association between family social background and general cognitive ability is slightly less strong than for women. The same applies for the association between family social background and adult academic attainment in the 1946 cohort. The association between general cognitive ability and academic attainment, on the other hand, was stronger for men than for women in the 1946 and 1958 cohort. In the 1970 cohort, the pathway coefficients were of similar size for men and women. The findings could thus indicate that for women in the earlier born cohorts, educational opportunities and the realization of cognitive potential were more constrained by social background factors, than for men. For the 1970 cohort, the findings suggest more gender equality in academic attainment. 
Table 4. Results from the Structural Equation Model linking Parental Social Status to general ability and academic attainment: Standardised Estimates, standard errors, and model fit for men and women in the three birth cohorts

\begin{tabular}{|c|c|c|c|c|c|c|}
\hline & \multicolumn{2}{|c|}{1946 Cohort } & \multicolumn{2}{|c|}{1958 Cohort } & \multicolumn{2}{|c|}{1970 Cohort } \\
\hline Measurement Model & Men & Women & Men & Women & Men & Women \\
\hline \multicolumn{7}{|l|}{ Parental Social Status (SES) } \\
\hline Father's occupational status & $.68(.02)$ & $.68(.02)$ & $.64(.02)$ & $.65(.02)$ & $.63(.02)$ & $.62(.01)$ \\
\hline Mother's education & $.78(.02)$ & $.75(.02)$ & $.73(.02)$ & $.73(.02)$ & $.73(.02)$ & $.72(.01)$ \\
\hline \multicolumn{7}{|l|}{ General Ability (g) } \\
\hline Verbal ability (BCS: definitions) & $.95(.01)$ & $.94(.01)$ & $.89(.01)$ & $.93(.01)$ & $.81(.01)$ & $.82(.01)$ \\
\hline Verbal ability (BCS: similarities) & & & & & $.76(.01)$ & $.75(.01)$ \\
\hline Non-verbal ability (BCS: matrixes) & $.87(.01)$ & $.85(.01)$ & $.88(.01)$ & $.87(.01)$ & $.57(.01)$ & $.56(.01)$ \\
\hline Non-verbal ability (BCS: digits) & & & & & $.40(.01)$ & $.39(.01)$ \\
\hline \multicolumn{7}{|l|}{ Academic Attainment (ACA) } \\
\hline Age leaving $\mathrm{ft}$ education & $.93(.01)$ & $.89(.01)$ & $.85(.01)$ & $.90(.01)$ & $.84(.01)$ & $.87(.01)$ \\
\hline Highest qualifications at age 26 & $.86(.01)$ & $.95(.01)$ & $.85(.01)$ & $.91(.01)$ & $.79(.01)$ & $.76(.01)$ \\
\hline \multicolumn{7}{|l|}{ Pathway Coefficients } \\
\hline $\mathrm{SES} \rightarrow \mathrm{g}$ & $-.53(.03)$ & $-.56(.03)$ & $-.45(.02)$ & $-.52(.02)$ & $-.60(.02)$ & $-.60(.01)$ \\
\hline
\end{tabular}


(Table 4 cont'd)

\begin{tabular}{|l|l|l|l|l|l|l|}
\hline $\mathrm{SES} \rightarrow \mathrm{ACA}$ & $-.54(.03)$ & $-.60(.03)$ & $-.48(.02)$ & $-.49(.02)$ & $-.54(.04)$ & $-.54(.03)$ \\
\hline $\mathrm{g} \rightarrow \mathrm{ACA}$ & $.46(.03)$ & $.37(.03)$ & $.46(.02)$ & $.37(.02)$ & $.28(.03)$ & $.27(.02)$ \\
\hline Model Fit & & & & & & \\
\hline $\mathrm{X}^{2}$ (df) & $12.41(6)$ & $6.67(6)$ & $50.44(6)$ & $19.01(6)$ & $97.32(15)$ & $67.78(15)$ \\
\hline $\mathrm{CFI}$ & 0.999 & 1.00 & 0.997 & 0.999 & 0.988 & 0.993 \\
\hline RMSEA & 0.022 & 0.008 & 0.033 & 0.018 & 0.037 & 0.028 \\
\hline $\mathrm{N}$ & 1937 & 1793 & 4792 & 4478 & 3519 & 3791 \\
\hline
\end{tabular}


Table 5. Logistic Regression. Predicting obtaining a degree level qualification by general cognitive ability, social background and gender (odds ratios and 95\% confidence interval)

\begin{tabular}{|c|c|c|c|}
\hline & $\operatorname{Exp}(B)$ & $95 \% \mathrm{Cl}$ & $\mathbf{p}$ \\
\hline General cognitive ability & 2.91 & $(2.62,3.23)$ & 0.000 \\
\hline \multicolumn{4}{|l|}{ Cohort (1946 as baseline) } \\
\hline 1958 cohort & 4.42 & $(3.77,5.17)$ & 0.000 \\
\hline 1970 cohort & 4.68 & $(3.17,6.91)$ & 0.000 \\
\hline \multicolumn{4}{|l|}{ Gender (male as baseline) } \\
\hline female & .75 & $(0.57,0.99)$ & 0.000 \\
\hline \multicolumn{4}{|c|}{$\begin{array}{l}\text { Parental Social Status (Professional } \\
\text { as baseline) }\end{array}$} \\
\hline Managerial/technical & .62 & $(0.51,0.77)$ & 0.000 \\
\hline Skilled non-manual & .44 & $(0.33,0.59)$ & 0.000 \\
\hline Skilled manual & .32 & $(0.22,0.48)$ & 0.000 \\
\hline Semi skilled & .24 & $(0.14,0.40)$ & 0.000 \\
\hline Unskilled & .17 & $(0.09,0.31)$ & 0.000 \\
\hline Mother's education & .51 & $(0.47,0.55)$ & 0.000 \\
\hline \multicolumn{4}{|l|}{ Interaction terms } \\
\hline Cohort x gender & 1.06 & $(0.97,1.15)$ & 0.183 \\
\hline Cohort x RGSC & 1.02 & $(0.99,1.06)$ & 0.203 \\
\hline Cohort x g & .90 & $(0.85,0.94)$ & 0.000 \\
\hline Gender x RGSC & .99 & $(0.93,1.06)$ & 0.823 \\
\hline Nagelkerke $\mathrm{R}^{2}$ & .30 & & \\
\hline
\end{tabular}


In a next step, a logistic regression was run to test the odds of obtaining a degree level qualification (NVQ4), simultaneously taking into account cohort membership, general cognitive ability, family social background, and gender - as well as the interactions between these variables. For the analysis, the data from all three data sets were pooled to enable the assessment of cohort differences. Table 5 gives the odd ratios and 95\% Confidence interval for the estimates. Controlling for general cognitive ability, the odds for obtaining a degree are higher in the later born cohorts (the 1946 cohort was used as the baseline). Women were less likely than men to gain a degree, as were those from relatively disadvantaged family backgrounds. The effect of socioeconomic factors is however stronger than gender effects. Of the interaction terms, only the interaction between cohort and general cognitive ability was significant, suggesting that, in the later born cohorts, high ability is not a sufficient condition for gaining a degree level qualification. Rather than suggesting that the linkage between cognitive ability and academic attainment has tightened, these results point in the opposite direction.

\section{Discussion}

The findings from the SEM model suggest that the strength of the association between family socioeconomic status and academic attainment has remained more or less the same for the three birth cohorts, while the association between general cognitive ability and academic attainment has reduced for the latest born 1970 cohort. Although the absolute rates of education participation have increased, relative differences between individuals from different social backgrounds have remained. The findings are in agreement with other studies based on the British cohort studies suggesting persisting social inequalities in attainment (Breen and Goldthorpe 2001; Bynner and Joshi 2002; Marshall, Swift and Roberts 1997).

Young people scoring high on the general cognitive ability tests at age 10-11 years have generally greater educational opportunities than low scorers, yet the findings also suggest that the predictive power of general cognitive ability has reduced, especially in the latest born cohort. The findings thus support the hypothesis that less able individuals from privileged backgrounds have benefited most from the educational expansion, not the most able (Blanden and Machin 2003; Bynner and Joshi
2002; Galindo-Rueda and Vignoles 2005; Marshall et al 1997; Schoon 2008), as the association between general cognitive ability and academic attainment has reduced for the 1970 cohort, while the association between social background and cognitive ability has increased. Despite considerable reforms of the education system in the UK, the findings suggest persistence of inequality in educational opportunity. This represents loss of talent and under-utilization of skills, since academic attainment should primarily be based on ability rather than socioeconomic background. On a positive note, gender inequalities in attainment appear to have reduced. However, although the gender gap is considerably smaller than inequalities associated with social background, after controlling for social background, significant gender differences in academic attainment remain.

Family social status at birth is significantly associated with general childhood cognitive ability. The observed associations do however not imply causal relationships between the factors, as there might be other explanatory processes not included in the model. The two variables share some genetic as well as environmental influences, and there is an ongoing debate about how these two variables are interlinked (Deary et al 2005; Flynn 2006). The paths in the model track development over time, yet the study cannot measure all the family characteristics that affect test scores and education; nor does it account for possible alternative explanations linking family social background and general cognitive ability to later academic attainment. Young people growing up in relative privileged families are likely to have better access to material and financial resources, role models, and parental encouragement (Duncan, Featherman and Duncan 1972; Featherman and Lerner 1985; Pilling 1990; Schoon 2006) than their less privileged peers. They might also have access to better schools, be treated differently by their teachers (Jencks 1979; Kerckhoff 2001; Marcenaro-Gutierrez, Galindo-Rueda and Vignoles 2007; Shavit and Featherman 1988), and choose different peers. Future studies should examine in more detail how characteristics of the family and the school environment affect test scores and subsequent attainment as well as other unmeasured characteristics including genetic effects.

In interpreting the findings, some other limitations of the study have to be acknowledged. The study has made use of data collected for three longitudinal studies, 
following cohort members born in 1946, 1958, and 1970 from childhood to early adulthood. As in most longitudinal studies, the analysis presented here is constrained by having to make best use of the available data, their measurement level and timing. In all three cohorts similar measures of parental social background and academic attainment could be identified, as well as measures of general cognitive ability at age 10-11 years, although different test instruments were used in the different studies. The test data has been standardized for comparison across cohorts, and SEM modeling was applied, using latent variables instead of direct measures for cohort comparison. Using theta parameterization, as implemented in the program Mplus 5 (Muthén and Muthén 2007), allowed the analysis of data on mixed measurement levels, although in interpreting the regression coefficients, the measurement level and assessment of the variables has to be taken into consideration, as well as the sample size, since smaller samples produce larger correlations.

Another issue to be addressed here is missing data, which might have affected the validity of the results. Response bias at the individual level would tend to underestimate the magnitude of effects of social disadvantage, as sample attrition is greatest among men and cohort members in more deprived circumstances (Plewis et al 2004). The problem of missingness in the data was addressed using multiple imputations as implemented in Mplus 5 (Muthén and Muthén 2007) as a 'best effort' technique. Nonetheless, the results might provide a conservative estimate of social inequalities in the sample.

Despite these concerns, the study provides an unique opportunity to assess changes in the association between family social background, gender, cognitive ability and academic attainment in a changing socio-historical context. General cognitive ability was directly assessed at entry to secondary school and prior to completing secondary schooling. It has been pointed out that IQ scores of children might be less reliable predictors than test scores of older individuals (Strenze 2007), although there is evidence of stability of intelligence during childhood (Burchinal et al 1997; Jensen 1980). However, correlations between IQ and subsequent educational and occupational success have shown to grow stronger as individuals grow older (Jencks 1970; Deary et al 2005; Schoon 2008). On the other hand, there is evidence to suggest that social origin factors have stronger effects on earlier transitions than on later ones (Mare 1980; Shavit and Blossfeld 1993; Jonsson, Mills and Müller 1996), and that socio-economic selection is more likely to occur at early stages of the educational career.

Increasing the school leaving age to 18 years, to be implemented in the UK by 2015, might provide a base for continued education participation for all. Current generations of young people expect and attain more education than previous ones, including those from less privileged backgrounds (Gregg and Macmillan, this issue; McVicar and Rice 2001; Schoon 2010). It has been argued that a new norm is emerging, promoting 'college for all', regardless of academic aptitude or social background (Schneider and Stevenson 1999; Reynolds and Pemberton 2001; Rosenbaum 1998). Further education for all is, however, not necessarily the solution to all problems, unless it will give students access to the same quality of education or jobs. In the USA nearly 70 per cent of high school students will begin a post-secondary experience, yet only a third of post-secondary students will complete a degree in a seven year period (NCES 2007). Moreover, many high school graduates find themselves unemployed after school or in casual, shortterm employment, and those who found employment were often only continuing the same dead-end jobs they already held during high school (Rosenbaum 2001).

Given the risk for failure, especially for those who are least prepared for further studies, or who can least afford it, there is a need to rethink the structure of support and educational policy. Policy makers are however torn between two conflicting pressures: the demand for greater access requires the expansion of the system, whereas the wish to maintain academic excellence requires more stringent selection on the basis of ability. When academic credentials are awarded indiscriminately they are devalued. Previous research has shown that a consequence of educational expansion in the 1980 was the creation of a bottleneck in the transition from secondary to tertiary education (Mare 1981; Shavit and Blossfeld 1993), where staying on beyond minimum school leaving age expanded massively, increasing students' expectations for a university education, while the tertiary level did not expand sufficiently to absorb the full extent of the new demand. As more young people, and in particular women, opted for admission into further and higher education, more stringent selection criteria were applied, which tended to exclude lower class applicants. 
The findings presented here suggest that the strength of the association between cognitive ability and academic attainment has reduced for the more recent cohort, indicating that high cognitive ability has not necessarily been rewarded in the changing education system. Children from disadvantaged backgrounds, starting their schooling at broadly the same high level of cognitive ability as other pupils, are falling behind in their course of education (Duckworth et al, this issue; Feinstein 2004; Schoon 2006), and are leaving school with lower levels of achievement than their less able peers from more privileged backgrounds. It is thus crucial to provide an educational environment that supports the realization of abilities and skills, avoids unnecessary waste of talent, and reduces the probability that social origin or gender determines destination in society, instead of ability. Evidence from the more recent age cohort, suggests that this picture of persisting social inequality in attainment, at least in secondary education, might be changing (Gregg and Macmillan, this issue). The long-term outcomes and returns to increasing education participation have yet to be assessed.

\section{Acknowledgements}

The analysis and writing of this chapter were supported by grants from the UK Economic and Social Research Council (ESRC): RES-225-25-2001 and RES-594-28-0001. Data from the Cohort Studies were supplied by the ESRC Data Archive. Thanks are also due to Michael Wadsworth for providing data from the 1946 cohort for analysis in this paper.

\section{References}

Arnot M, David M and Weiner G. (1999) Closing the gender gap. Polity Press , Cambridge.

Bentler PM. (1990) Comparative fit indexes in structural models. Psychological Bulletin, 107(2), 238-246.

Blanden J and Machin S. (2003) Educational inequality and the expansion of UK higher education. London School of Economics, Centre for Economic Performance, London.

Blossfeld H-P. (2005) Globalization, uncertainty and youth in society. Routledge, London.

Blossfeld H-P and Hofmeister HA. (2006) Globalization, uncertainty and women's careers : an international comparison. Edward Elgar, Cheltenham.

Blossfeld H-P and Shavit Y. (1993) Persisting barriers. Changes in educational opportunities in thirteen countries. In Persistent inequality : changing educational stratification in thirteen countries (pp. 1-23). Westview Press, Boulder, Co.

Bollen KA. (1989) Structural equations with latent variables. Wiley, New York.

Bond R and Saunders P. (1999) Routes to success: influences on the occupational attainment of young British males. British Journal of Sociology, 50, 217-249.

Bowles S. (1972) Schooling and inequality from generation to generation. Journal of Political Economy, 80, 219251.

Breen R and Goldthorpe JH. (2001) Class, mobility and merit - the experience of two British birth cohorts. European Sociological Review, 17(2), 81-101.

Burchinal MR, Campbell FA, Bryant DM, Wasik BH and Ramey CT. (1997) Early intervention and mediating processes in cognitive performance of children of low-income African-American families. Child Development, 68, 935-954.

Bynner J. (2001) British youth transitions in comparative perspective. Journal of Youth Studies, 4(1), 5-23.

Bynner J. (2005) Rethinking the youth phase of the life course: the case for emerging adulthood. Youth and Society, 8(4), 367-384.

Bynner J and Joshi H. (2002) Equality and opportunity in education: evidence from the 1958 and 1970 birth cohort studies. Oxford Review of Education, 28(4), 405-425.

Bynner J and Parsons S. (2002) Social exclusion and the transition from school to work: the case of young people not in education, employment, or training (NEET). Journal of Vocational Behaviour, 60(2), 289-309.

Deary IJ, Strand S, Smith PK and Fernances C. (2007) Intelligence and educational achievement. Intelligence, 35, 13-21.

Deary IJ, Taylor MD, Hart CL, Wilson V, Davey Smith G, Blane D et al. (2005) Intergenerational mobility and midlife status attainment: influences of childhood intelligence, childhood social factors, and education. Intelligence, 33, 455-472.

Douglas JWB. (1964) The home and the school: a study of ability and attainment in the primary school. MacGibbon and Kee, London. 
Duncan OD, Featherman DL and Duncan B. (1972) Socio-economic background and achievement. Seminar Press, New York.

Dykiert D, Gale CR and Deary IJ. (2009) Are apparent sex differences in mean IQ scores created in part by sample restriction and increased male variance? Intelligence, 37(1), 42-47.

Elliott CD, Murray D and Pearson L. (1979) British ability scales. National Foundation for Educational Research (NFER), Slough.

Epstein D, Elwood J, Hey V and Maw J. eds. (1998) Failing Boys? Open University Press, Buckinghamshire.

Featherman DL and Lerner RM. (1985) Ontogenesis and sociogenesis - problematics for theory and research about development and socialization across the lifespan. American Sociological Review, 50(5), 659-676.

Feinstein L. (2004). Mobility in pupils' cognitive attainment during school life. Oxford Review of Economic Policy, 20(2), 213-229.

Ferri E, Bynner J and Wadsworth MEJ. (2003) Changing Britain, changing lives: three generations at the turn of the century. Institute of Education, London.

Flynn JR. (2004) IQ trends over time: intelligence, race and meritocracy. In K Arrow, S Bowles and S Durlauf. eds. Meritocracy and economic inequality (pp. 35-60). Princeton University Press, Princeton, NJ.

Flynn JR. (2006) Towards a theory of intelligence beyond g. Behavioral and Brain Sciences, 29(2), 132-133.

Francis B. (2000) Boys, girls and achievement: addressing the classroom issues. Routledge Falmer, London.

Francis B. (2002) Is the future really female? The impact and implications of gender for 14-16 year olds' career choices. Journal of Education and Work, 15(1), 75-88.

Furlong A and Cartmel F. (1997) Young people and social change. Open University Press, Buckingham.

Gallie D. (2000) The labour force. In AH Halsey and J Webb. eds. Twentieth Century British Social Trends pp. 281323. Macmillan, London.

Galindo-Rueda F and Vignoles A. (2005) The declining relative importance of ability in predicting educational attainment Journal of Human Resources, 40(2), 335-353.

Gershuny J. (2000) Social position from narrative data. In R Crompton, F Devine, M Savage and J Scott. eds. Renewing class analysis. Blackwell/The Sociological Review, Oxford.

Goyette KA. (2008) College for some to college for all: social background, occupational expectations and educational expectations over time. Social Science Research, 37, 461-484.

Gottfredson, LS. (1997) Why g matters: the complexity of everyday life. Intelligence, 24, 79-132.

Hauser RM and Huang MH. (1997) Verbal ability and socio-economic success: a trend analysis. Social Science Research, 16, 331-376.

Hobsbawm EJ. (1995) The age of extremes: the short twentieth century, 1914-1991. Abacus, London.

Herrnstein RJ and Murray C. (1994) The bell curve. Intelligence and class structure in American life. Free Press, New York.

Jensen AR. (1998) The $g$ factor. The science of mental ability. Praeger, Westport.

Kerckhoff, AC. (2001) Education and social stratification processes in comparative perspective. Sociology of Education, (Extra Issue) 3-18.

Kerckhoff AC and Trott JM. (1993) Educational attainment in a changing educational system. In Y Shavit and H-P Blossfeld. eds. Persistent inequality : changing educational attainment in thirteen countries (pp. 133156). Westview Press, Boulder, Colo.

Korenman S, Miller JE and Sjaastad JE. (1995) Long-term poverty and child development: evidence from the NLSY. Children and Youth Services Review, 17(1-2), 127-155.

Krieger N, Williams DR and Moss NE. (1997) Measuring social class in US public health research: concepts, methodologies, and guidelines. Annual Review of Public Health, 18, 341-378.

Lampard R. (1995) Parents' occupation and their children's occupational attainment: a contribution to the debate on the class assignment of families. Sociology, 29, 715-728.

Leete R and Fox J. (1977) Registrar General's social classes: origins and users. Population Trends, 8, 1-7.

Little RJA and Rubin DB. (2002) Statistical analysis with missing data, 2nd edition. Wiley, Hoboken.

Lynn R. (1999). Sex differences in intelligence and brain size: a developmental theory. Intelligence, 27(1), 1-12.

Mackintosh NJ. (1998) IQ and human intelligence. Oxford University Press, Oxford.

Makepeace G, Dolton P, Woods L, Joshi H and Galinda-Rueda F. (2003) From school to the labour market. In E Ferri, J Bynner and MEJ Wadsworth. eds. Changing Britain, changing lives: three generations at the turn of the century (pp. 29-70). Institute of Education, London.

Marcenaro-Gutierrez O, Galindo-Rueda F and Vignoles A. (2007) Who actually goes to university? Empirical Economics, 32(2-3), 333-357.

Mare RD. (1981) Change and stability in educational stratification. American Sociological Review, 46, 72-87

Marini MM and Fan P-L. (1997) The gender gap in earnings at career entry. American Sociological Review, 62, 588-604. 
Marsh C. (1986) Social class and occupation. In RG Burgess. ed. Key variables in social investigation. Routledge, London.

Marshall G, Swift A and Roberts S. (1997) Against the odds?: social class and social justice in industrial societies. Clarendon Press, Oxford.

McVicar D and Rice P. (2001) Participation in further education in England and Wales: an analysis of post-war trends. Oxford Economics Papers, 53, 47-66.

Murnane R J, Willet J B and Levy F. (1995) The growing importance of cognitive skills in age determination. Review of Economics and Statistics, 87, 235-255.

Muthén LK and Muthén BO. (2007) Mplus user's guide. 5th edition, Muthén and Muthén, Los Angeles, CA.

Office for Population and Census Studies (1980) Classification of occupations and coding index. HMSO, London.

Pilling D. (1990) Escape from disadvantage. Falmer Press, London.

Richards M, Power C and Sacker A. (2009) Paths to literacy and numeracy problems: evidence from two British birth cohorts. Journal of Epidemiology and Community Health, 63(3), 239-244.

Richards M and Sacker A. (2003) Lifetime antecedents of cognitive reserve. Journal of Clinical and Experimental Psychology, 25, 614-624.

Riddell S. (2000) Equal opportunities and educational reform in Scotland: the limits of liberalism. In JAR Salisbury. ed. Gender, policy and educational change. Routledge, London.

Rosenbaum JE. (1998) College-for-All: do students understand what college demands? Social Psychology of Education, 2, 55-80

Rosenbaum J. (2001). Beyond college for all: career paths for the forgotten half. Russel Sage Foundation, New York.

Saunders P. (1997) Social mobility in Britain: an empirical evaluation of two competing theories. Sociology, 31, 261-288.

Saunders P. (2002) Reflections on the meritocracy debate in Britain: a response to Richard Breen and John Goldthorpe. British Journal of Sociology, 53, 559-574.

Schoon I. (2006) Risk and resilience. Adaptations in changing times. Cambridge University Press, Cambridge.

Schoon I. (2008) A transgenerational model of status attainment: the potential mediating role of school motivation and education. National Institute Economic Review, 205, 72-82.

Schoon I. (2010) Planning for the future: changing education expectations in three British cohorts. Historical Social Research, 35(2), 99-119

Schoon I, Martin P and Ross A. (2007) Career transitions in times of social change. His and her story. Journal of Vocational Behavior, 70(1), 78-96.

Schneider B and Stevenson D. (1999) The ambitious generation: America's teenagers, motivated but directionless. Yale University Press, New Haven.

Scott J, Dex S, Joshi H, Purcell K and Elias P. eds. (2008) Women and employment: changing lives and new challenges. Edward Elgar, Northampton.

Shavit $Y$ and Blossfeld H-P. (1993) Persistent inequality : changing educational attainment in thirteen countries. Westview Press, Boulder, Colo.

Shavit $Y$ and Featherman DL. (1988) Schooling, tracking, and teenage intelligence. Sociology of Education, 61(1), 42-51.

Strand S, Deary IJ and Smith P. (2006) Sex differences in cognitive abilities test scores: a UK national picture. British Journal of Educational Psychology, 76, 463-480.

Sternberg RJ, Grigorenko EL and Bundy DA. (2001) The predictive value of IQ. Merrill-Palmer Quarterly, 47, 1-41.

Strenze T. (2007) Intelligence and socioeconomic success: a meta-analytic review of longitudinal research. Intelligence, 35(5), 401-426.

Tinklin T. (2003) Gender differences and high attainment. British Educational Research Journal, 29(3), 307-325.

Wadsworth MEJ, Kuh D, Richards M, Hardy R. (2005) Cohort profile: the 1946 National Birth Cohort (MRC National Survey of Health and Development). International Journal of Epidemiology, 35, 49-54

Younger M and Warrington M. (2006) Raising boys' achievement. Department for Education and Skills, Research Report RR636.

\section{Endnotes}

\footnotetext{
'The occupational categories used in the US census and other European countries are similarly based on the skills and status of different occupations (Krieger, Williams, \& Moss, 1997).
} 